\title{
Study of Blood-Pressure Measurement Using Noninvasive Methods ${ }^{+}$
}

\author{
Mariña González-Pena *(D), Juan A. Castro-García *(D), Alberto J. Molina-Cantero (D), Manuel Merino-Monge (D) and \\ Isabel M. Gómez-González (D)
}

Departamento de Tecnología Electrónica, ETS, Ingeniería Informática, Universidad de Sevilla, 41012 Sevilla, Spain; almolina@us.es (A.J.M.-C.); manmermon@dte.us.es (M.M.-M.); igomez@us.es (I.M.G.-G.)

* Correspondence: marinagonzalezpena10@gmail.com (M.G.-P.); jacastro@us.es (J.A.C.-G.)

+ Presented at the 4th XoveTIC Conference, A Coruña, Spain, 7-8 October 2021.

check for

updates

Citation: González-Pena, M.; Castro-García, J.A.; Molina-Cantero, A.J.; Merino-Monge, M.; Gómez-González, I.M. Study of Blood-Pressure Measurement Using Noninvasive Methods. Eng. Proc. 2021, 7, 8. https://doi.org/10.3390/ engproc2021007008

Academic Editors: Joaquim de Moura, Marco A. González, Javier Pereira and Manuel G. Penedo

Published: 29 September 2021

Publisher's Note: MDPI stays neutral with regard to jurisdictional claims in published maps and institutional affiliations.

Copyright: (C) 2021 by the authors. Licensee MDPI, Basel, Switzerland. This article is an open access article distributed under the terms and conditions of the Creative Commons Attribution (CC BY) license (https:// creativecommons.org/licenses/by/ $4.0 /)$.

\begin{abstract}
The correct diagnosis of high blood pressure is important to avoid cardiovascular diseases. In this work, we propose a low-cost noninvasive blood-pressure measurement unit composed of a photoplethysmograph and an electrocardiograph. It is based on pulse transit time measurement, thus performing nonocclusive measurement. To test the effectiveness of this parameter, a total of five subjects were measured, verifying their effectiveness at all times.
\end{abstract}

Keywords: blood pressure; PTT; pulse transit time; PPG; ECG

\section{Introduction}

Cardiovascular diseases are a group of disorders related to the circulatory system that may affect the heart. According to the World Health Organisation World Health Organisation (WHO), 17.9 million people die from cardiopathy, with high blood pressure (BP) being one of the major risk factors for cardiovascular disease [1]. The periodic measurement of the BP is recommended. Some methods for it have the disadvantage of being occlusive, which may cause discomfort to patients, apart from requiring health personnel. In recent years, a method of BP measurement based on the pulse wave velocity (PWV) concept has been investigated, which has the great advantage of being nonocclusive.

PWV is defined as the velocity of pressure pulses as they propagate along the arterial tree. Any variation in the biomechanical properties of the aorta induces changes in pulse propagation velocity; see [2] for further details. In general, different proposals are based on the following simplification: given an arterial segment of length $D$, the PWV is defined as quotient of $\mathrm{D}$ divided by pulse transit time (PTT) $P W V=D / P T T$, where PTT isthe time of flight of the pressure wave. More exactly, PTT corresponds to the difference between the arrival times of the pressure pulse at the distal end and the proximity of the heart $P T T=P A T_{d}-P A T_{p}$ (see Figure 1 ). The wave peak $\mathrm{R}$ of the electrocardiography (ECG) offers information about when heart contraction starts. Thus, it represents to some extent $P A T_{p}$ time, while the systolic peak of the photoplethysmography (PPG) indicates the distal $P A T_{d}$. 


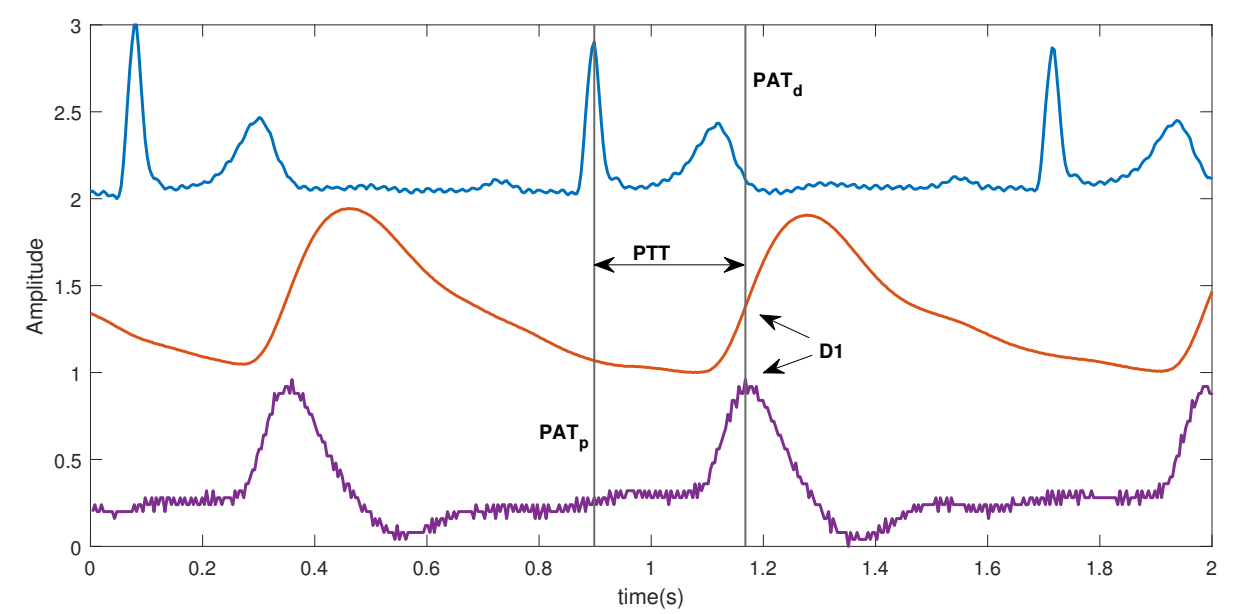

Figure 1. ECG (blue), PPG (orangle), and VPG (purple). Signal amplitudes were normalized.

\section{Materials and Methods}

With the aim of quantifying the PTT, an Arduino shield called Galicia was developed. It contains an ECG and a PPG. An Arduino Uno, programmed using library BSP [3] at $256 \mathrm{~Hz}$ of sampling frequency, has only been used for data acquisition. The ECG circuit was presented in [4], with electrodes placed following the Einthoven lead II schema. The PPG is formed by an TCRT100, a high-pass filter with a cut-off frequency of $0.7 \mathrm{~Hz}$, a low pass filter of $28.2 \mathrm{~Hz}$, and a total gain of 100. In order to make the design portable, an external battery was added along with an expansion port for a Bluetooth connection through the HC05 module. Between the R peak of the ECG signal and the systolic peak of the PPG signal, there is a delay of the order of hundreds of milliseconds that remains constant throughout the measurement. This delay obeys the response time between the electrical activation of the myocardium and the mechanical ejection of the ventricular blood towards the aorta. In the ECG signal, the R peak is the most commonly used critical point, whereas for the PPG, there is no defined convention for this point. In this case, the maximum of the first derivative of the PPG signal, the so-called velocity of PPG (VPG), was chosen; this point is also known as D1. The Pan-Tompkins algorithm [5] is used for the detection of the $R$ and $D 1$ points in offline processing.

The principal aim of the development of this study was to use the concept of PTT to estimate arterial BP, finding out the relationship among systolic pressure (SP), arm length, and PTT. In addition, the effect of physical exercise on BP reduction was analyzed to process ECG and PPG data taken from a total of five people ( 3 men and 2 women) with an age range of 22 to 34 years. Only one participant, S2, had been subjected to a $2.5 \mathrm{~min}$ of soft exercise before the corresponding measurements were taken, to verify that there was a decrease in BP [6].

The method is similar for both situations and comprises the following steps: (1) measurement of diastolic and SP before of the experiment using a sphygmomanometer; (2) armlength measurement; (3) ECG and PPG data recorded for $2.5 \mathrm{~min}$, and (4) measurement of diastolic and SP. During Step (3), all volunteers were at rest except in the physical condition, in which one volunteer was pedalling.

\section{Results and Discussions}

The following relationships were analysed: SP, arm length, and PTT. First, a higher PTT value is related to a higher BP, as Table 1 shows, where the participant with less arterial pressure was the one who had less PTT. The relationship between PTT and the ratio of SP to arm length (SPAL) was then analyzed. The definition of PTT shows that the lower the value of such a ratio is, the lower the PTT (SPAL in Table 1), with the exception of participant S2, who did not fulfil this condition. Therefore, the existence of a relationship between PTT and systolic pressure was demonstrated. According to the consulted bibliography, this 
relationship can be very useful in the detection of patients in a sleep unit since it provides relevant information about refractory hypertension [7].

Lastly, for participant S2 who was performing physical exercise for $2 \mathrm{~min} 30 \mathrm{~s}$, blood pressure obtained prior and after working out was compared. PTT decreased when the subject underwent physical activity, which agreed with some published studies [8]. Although obtained results were conclusive with the consulted bibliography, they were not statistically significant since the tests were performed only on five people.

Table 1. BP, heart rate (HR), arm length, PTT and SPAL per participant.

\begin{tabular}{cccccccc}
\hline ID & $\begin{array}{c}\text { BP-Pre } \\
(\mathbf{m m H g})\end{array}$ & $\begin{array}{c}\text { HR-Pre } \\
(\mathbf{b} \mathbf{m})\end{array}$ & $\begin{array}{c}\text { BP-Post } \\
(\mathbf{m m H g})\end{array}$ & $\begin{array}{c}\text { HR-Post } \\
\mathbf{( b \mathbf { m m } )}\end{array}$ & $\begin{array}{c}\text { Arm Length } \\
\mathbf{( m )}\end{array}$ & $\begin{array}{c}\text { PTT } \\
(\mathbf{m s})\end{array}$ & $\begin{array}{c}\text { SPAL } \\
(\mathbf{m m H} / \mathbf{m})\end{array}$ \\
\hline 1 & $100 / 67$ & 91 & $101 / 70$ & 83 & 0.700 & 251 & 143 \\
\hline 2 & $123 / 74$ & 67 & $110 / 65$ & 61 & 0.855 & 301 & 144 \\
\hline 3 & $125 / 81$ & 83 & $120 / 82$ & 83 & 0.830 & 262 & 151 \\
\hline 4 & $145 / 72$ & 86 & $119 / 73$ & 61 & 0.835 & 305 & 174 \\
\hline 5 & $121 / 77$ & 58 & $113 / 76$ & 58 & 0.730 & 298 & 165 \\
\hline $2_{e}$ & $112 / 75$ & 75 & $103 / 65$ & 64 & 0.855 & 266 & 131 \\
\hline
\end{tabular}

Two devices based on this technology are currently on the market: the ASUS VivoWatch BP and the RT1025 Cardioid PAD. Both integrate ECG and PPG sensors with a cost of EUR 139 and EUR 75.75, respectively. The price of these devices is far from the one designed for this work, which costs EUR 25.

\section{Conclusions}

In this work, we used the concept of PTT for the measurement of BP using electrocardiographic and photoplethysmographic signals. The relationship among concepts such as PTT, SP or PTT, and physical exercise were tested. In summary, the designed hardware device, PCB GALICIA, fulfilled the initial objective, being useful for analyzing PPG and ECG signals.

Funding: This research was funded by Spanish Ministry of Science and Innovation, State Plan 2017-2020: Challenges—R\&D\&I Projects with grant codes PID2019-104323RB-C32.

Institutional Review Board Statement: The study was conducted according to the guidelines of the Declaration of Helsinki, and approved by the Ethics Committee of Junta de Andalucía (protocol code C.P. TAIS-C.I. 1130-N-17, 2018).

Informed Consent Statement: Informed consent was obtained from all subjects involved in the study.

Conflicts of Interest: The authors declare no conflict of interest.

\section{References}

1. World Health Organization. Cardiovascular Diseases (CVDs). 2021. Available online: https://www.who.int/en/news-room/ fact-sheets/detail/cardiovascular-diseases-(cvds) (accessed on 8 September 2021).

2. Solà i Carós, J.M. Continuous Non-Invasive Blood Pressure Estimation. Ph.D. Thesis, ETH Zurich, Zurich, Switzerland, 2011.

3. Molina-Cantero, A.J.; Castro-García, J.A.; Lebrato-Vázquez, C.; Gómez-González, I.M.; Merino-Monge, M. Real-Time Processing Library for Open-Source Hardware Biomedical Sensors. Sensors 2018, 18, 1033. [CrossRef] [PubMed]

4. Castro-García, J.A.; Molina-Cantero, A.J.; Merino-Monge, M.; Gómez-González, I.M. An Open-Source Hardware Acquisition Platform for Physiological Measurements. IEEE Sens. J. 2019, 19, 11526-11534. [CrossRef]

5. Pan, J.; Tompkins, W.J. A Real-Time QRS Detection Algorithm. IEEE Trans. Biomed. Eng. 1985, BME-32, 230-236. [CrossRef] [PubMed]

6. Ferrer Mileo, V. Estudio de la Viabilidad de la Estimación del Grado de Adherencia a Estilos de Vida Saludables a Partir de Medidas Cardíacas Oportunistas. Ph.D. Thesis, Universitat Politècnica de Catalunya, Barcelona, Spain, 2019. 
7. Gómez García, M.T.; Troncoso Acevedo, M.F.; Rodriguez Guzmán, M.; Alegre de Montaner, R.; Fernández Fernández, B.; del Río Camacho, G.; González-Mangado, N. Can Pulse Transit Time Be Useful for Detecting Hypertension in Patients in a Sleep Unit? Arch. Bronconeumol. 2014, 50, 278-284. [CrossRef] [PubMed]

8. Mateu-Mateus, M.; Guede-Fernández, F.; García-González, M.A.; Ramos-Castro, J.J.; Fernández-Chimeno, M. Camera-Based Method for Respiratory Rhythm Extraction From a Lateral Perspective. IEEE Access 2020, 8, 154924-154939. [CrossRef] 